\title{
Advances in Atopic dermatitis
}

\author{
Natalija Novak ${ }^{\mathrm{a}}$ and Donald Y.M. Leung ${ }^{\mathrm{b}, \mathrm{c}}$ \\ ${ }^{a}$ Department of Dermatology and Allergy, University of Bonn, Sigmund-Freud Str. 25, D-53105 \\ Bonn, Germany Natalija.Novak@ukb.uni-bonn.de \\ bepartment of Pediatrics, National Jewish Health, 1400 Jackson Street, Denver, Colorado \\ 80206 USA
}

\begin{abstract}
Atopic Dermatitis (AD) results from barrier defects combined with modified immune responses of the innate and the adaptive immune system to exogenous and endogenous factors. Recent research has continued to sort out the complex pathophysiologic puzzle of this frequent skin disease. However, the network of mechanisms leading to the manifestation of $\mathrm{AD}$ is far from being completely understood. Nonetheless, there is evidence that common mechanisms are shared by a majority of patients, while individual disease-triggering pathways might be dominant in particular subgroups of AD patients. Thus, detailed knowledge about the pathophysiologic pathways underlying this disease is essential for the development of mechanism-based, therapeutic approaches.
\end{abstract}

\section{Introduction}

The interplay of a multitude of factors leads to manifestations of the most frequent chronic inflammatory skin disease in the western world, called atopic dermatitis (AD). AD is characterized by acute flare ups as well as chronic eczematous pruritic skin lesions over dry skin. It is caused by an impaired skin barrier, complex immune dysregulation and amongst other factors, IgE-mediated mechanisms [1]. It has been a matter of debate for a long time, whether the disturbed skin barrier, which is a characteristic feature of $\mathrm{AD}$, or the hyperreactive immune system on the other hand represent a primary or secondary cause of this disease. Arguments for a strong role of a genetically predetermined skin barrier disturbance came largely from the discovery of associations of loss-of function mutations in the pro-filaggrin $(F L G)$ gene with $\mathrm{AD}$. Pro-filaggrin is an important precursor of filaggrin, a key structural protein of the upper epidermal layer. Genetic associations of $F L G$ mutations with $\mathrm{AD}$ were confirmed and further verified by many independent groups using numerous cohorts of Caucasian and Northern-American AD patients. These studies defined FLG mutations as the strongest genetic association with AD described so far. Furthermore, lossof function mutations in the $F L G$ gene predispose AD patients to sensitization with environmental factors, and leads to severe chronic AD, peanut allergy [2], hand eczema [3] or development of asthma in $\mathrm{AD}$ patients $[4,5]$.

(C) 2011 Elsevier Ltd. All rights reserved.

${ }^{\mathrm{C}}$ Corresponding author: Donald YM Leung, MD, PhD National Jewish Health 1400 Jackson Street, Rm K926i Denver, Colorado 80206 USA Tel: 303-398-1379; Fax: 303-270-2182; leungd@ njhealth.org.

Publisher's Disclaimer: This is a PDF file of an unedited manuscript that has been accepted for publication. As a service to our customers we are providing this early version of the manuscript. The manuscript will undergo copyediting, typesetting, and review of the resulting proof before it is published in its final citable form. Please note that during the production process errors may be discovered which could affect the content, and all legal disclaimers that apply to the journal pertain. 
In addition to the function of filaggrin in bundling keratin filaments and compaction of the upper epidermis, filaggrin degradation products are a source of natural moisturizing factor (NMF) in the stratum corneum. Although the level of NMF, including urocanic acid (UCA9 and pyrrolidone carboxyclid acid (PCA) is reduced in $\mathrm{AD}$ independently from $F L G$ mutations, the $F L G$ mutation status tightly determines the level of NMF reduction [6,7]. It has also been hypothesized that the lower acidification of the skin caused by reduced filaggrin metabolites acts on skin barrier impairment in AD as well. In this context it has been demonstrated that UCA and PCA reduce growth rates of Staphylococcus aureus ( $S$. aureus) by lowering the secretion and expression of cell wall proteins necessary for its colonization and immune evasion [8]. Thus, reduced filaggrin levels due to FLG mutations might secondarily enhance the rate of $S$. aureus colonization and thereby increase the severity of AD.

However, since only one third of $\mathrm{AD}$ patients have been identified as $F L G$ mutation carriers, other genetic and environmental co-factors might additionally act on skin barrier function [9]. In line with this assumption, a genome wide association study revealed the association of a common variant on chromosome 11q13 as well as a variant on chromosome 1q21 with $\mathrm{AD}$ [10]. The association of the chromosome 11q13.5 variant with AD has been confirmed in independent cohorts for childhood eczema [11] as well as allergic asthma and hay fever [12]. Since the same risk allele had been reported to be associated with Crohn's disease, this genetic modification might go along with chronic epithelial inflammation and barrier dysfunction in general. However, further functional analyses are required to elucidate the exact relevance of genetic modifications in AD. The second associated region on chromosome 1q21 encodes a protein important for keratinocyte differentiation, named hornerin, with quite similar functions to filaggrin. Recently, it has been demonstrated that hornerin is present in the epidermal cornified envelope, which together with presumed lower hornerin expression in $\mathrm{AD}$ skin points to another possible genetically predetermined skin barrier defect of the stratum corneum in $\mathrm{AD}$ [13]. In general, the physical skin barrier consists of two parts, the stratum corneum and tight junctions, which are important components for paracellular passage of soluble mediators and keratinocyte function. Reduced expression of claudin-1, which belongs to a family of transmembrane proteins in AD skin has been demonstrated and has been linked to AD by association of a single nucleotide polymorphism in the gene region encoding claudin-1 [13]. This genetic modification might lead to barrier dysfunction and predispose certain AD patients to disseminated viral skin infections [14].

\section{Features of lesional and non-lesional skin}

Not only lesional, but also clinically non-lesional skin of AD patients is different from healthy skin. Lower hydration, modified lipid synthesis, decreased epidermal differentiation and infiltration of $\mathrm{T}$ cells have been described as characteristic features in the past. More detailed insights into the differences in terminal differentiation and immune responses have been reported in recent genomic and histologic profiling approaches, comparing lesional versus non-lesional AD skin within the same individuals [15]. Increased epidermal thickness and proliferation as well as a dermal infiltrate consisting of $\mathrm{CD}^{+} \mathrm{T}$ cells and CD11 $\mathrm{c}^{+} \mathrm{DCs}$ characterizes non-lesional AD skin. A panel of genes encoding proteins involved in the epidermal proliferation process are downregulated in lesional AD skin as opposed to healthy non-AD skin. Moreover, expression of Th1, Th2 and T22 proteins is increased even in nonlesional AD skin. In contrast, cytokine and chemokine genes consistent with allergic inflammation are directly related to severity of $\mathrm{AD}$, and upregulated in non-lesional $\mathrm{AD}$ skin, but further induced in lesional AD skin. Additionally, epidermal skin barrier protein expression including filaggrin-2, coneodesmosin, desmoglein-1, desmocollin-1, transglutaminase- 3 as well as arginase-1, caspase-14 and gamma-glutamyl-cyclotransferase 
as components of natural moisturizing factor generation are lower in lesional than in nonlesional AD skin [16]. Beyond, the immunologic importance that allergens, such as mite allergens have in stimulating effector cells and antigen presenting cells, allergens also activate keratinocytes. House dust mite allergens activate caspase- 1 related release of IL- $1 \beta$ and IL-18 by skin keratinocytes and activate the inflammasome via the nucleotide-binding oligomerization domain, leucine-rich repeat and pyrin-domain containing 3 (NLRP3) [17]. The inflammasome is a central part of the innate immune system, detecting and mediating danger signals. Based on this data, deficient signaling via the inflammasome pathway might be of pathophysiologic relevance in AD. Furthermore, attenuated toll-like receptor (TLR)2 mediated signaling and release of proinflammatory cytokines, chemokines or matrix metalloproteinases by primary keratinocytes from AD patients has been described. Together, modified functions of keratinocytes might promote inflammation in response to allergens or microbial components in AD [18]. Beyond, eczema formation it has been observed to go along with enhanced activation and apoptosis of keratinocytes. Among other factors, the tumor necrosis factor (TNF)-like weak inducer of apoptosis (TWEAK) has been shown to be overexpressed in keratinocytes in lesional AD skin [19]. Moreover, expression of the fibroblast growth factor-inducible 14, the receptor for TWEAK, was enhanced in AD skin as well. This suggests a role for TWEAK in keratinocyte death leading to spongiosis and eczema development.

\section{A Role for Soluble Factors in the Circulation and the Skin}

In a majority of $\mathrm{AD}$ patients, total serum $\operatorname{IgE}$ serum and allergen specific IgE are increased. It is still unclear, however, whether serum IgE represents just a co-factor of the disease or directly impacts relevant pathways in AD. Support for the latter hypothesis comes from observations gained in patients with Hyper-IgE syndrome (HIES), an immunodeficiency which is accompanied by frequent $S$. aureus infections as well as eczema. A high number of HIES patients carries STAT3 mutations and monocytes and monocyte-derived DCs generated from those patients display a reduced capacity to respond to IL-10. Consequently, they fail to induce a regulatory DC phenotype and Foxp3+ $\mathrm{T}$ regs from naïve $\mathrm{T}$ cells in vitro. This attenuated protolerogenic pathway exemplifies in which direction $S$. aureus driven superinfections might contribute to uncontrolled skin inflammatory mechanisms [20]. Another interesting connection between S. aureus and IgE-mediated mechanisms in AD arises from the identification of an IgE-reactive DNA clone, which encodes S. aureus derived fibronectin-binding protein [21]. Experiments with recombinant fibronectin binding protein revealed that induction of $T$ cell reactivity requires antigen presentation of the fibronectin binding protein. The connection between IgE reactivity to $S$. aureus components mediated by antigen presenting cells further explains the multiple ways in which $S$. aureus and its products might serve as important amplifiers of the disease [22].

Since the discovery of increased TSLP expression in the epidermis of lesional AD, TSLP is regarded as another important co-factor, capable of enhancing the Th2 polarizing properties of DCs in allergic skin inflammation [23]. TSLP is expressed constitutively in epithelial cells such as keratinocytes. Interestingly, it has been shown recently that simple mechanical injury is capable of upregulating TSLP levels in the skin in mouse models, subsequently leading to an increased Th2 immune response driven by TSLP-activated skin DCs [24]. Based on this model, chronic skin injury, e.g induced by scratching, might elicit Th2 immune response. This further aggravates the course of AD causing a vicious circle between scratching, mechanical damage, TSLP activation and Th2 upregulation. Moreover, TSLP not only activates DCs and B cells but also invariant natural killer cells in vitro, which secrete enhanced levels of IL-4 and IL-13 in response to TSLP stimulation [25]. These T cells express both the semi-invariant $\mathrm{T}$ cell receptor (TCR) and the NK cell receptor 
(CD161) linking innate and adaptive immunity by their cytotoxic functions [26]. However, whether invariant NK cells play a role in AD remains to be elucidated.

\section{Secondary factors modifying DC function}

Myeloid DC subtypes in the skin have been identified to play a key role in allergen uptake and antigen stimulation [27] . DC activated with wash fluid derived from AD lesions released several proinflammatory cytokines [28]. Lipoteichoic acid derived from S. aureus has been identified as the main component responsible for this effect. These results point to the role of bacterial infections in triggering AD by activating skin DCs. Moreover, the tetraspanins CD9 and CD81, which have been demonstrated to be highly expressed by epidermal DCs in lesional AD might amplify FceRI activation on DC in vivo [29]. Tetraspanins exert their functions mainly be regulating cell-type specific protein-protein interactions, which might occur even independently and even without binding of exogenous ligands to the tetraspanins itself. Thus, association of CD9 and CD81 with FceRI on human antigen presenting cell might co-regulate and amplify Fc\&RI mediated signals in vivo and explain in part the versatile functions of FceRI on human DCs.

Lower IFN- $\gamma$ receptor expression and attenuated IFN- $\gamma$ response of skin DCs and their precursor cells might represent another important co-factor leading to attenuated Th1 driven immune responses in $\mathrm{AD}$ [30]. A modified responsiveness of skin DCs in AD to Th1 stimuli might in part explain the attenuated Th1 immune responses despite presence of a significant amount of Th1 cytokines as well as strong Th1 stimuli in the cellular micromilieu.

Experiments with enriched epidermal Langerhans cells, inflammatory dendritic epidermal cells as well as blood-dendritic cells antigen-1 positive and negative DCs from lesional AD skin, skin of psoriasis patients and healthy volunteers revealed a similar constitutive capacity of those cells to induce Th1, Th2, Th17 and Th22 driven immune responses in allogeneic responder cells in vitro [31].

The data suggests that unstimulated skin DCs might have the capacity to prime all types of $\mathrm{T}$ cell responses. Genetic background, factors in the micromilieu related to the respective skin disease and within the lymphatic organs, nature of stimulating antigens, concomitant FceRI activation and numerous other factors might in vivo secondarily direct the nature of the $\mathrm{T}$ cell responses induced. Due to the constitutive capacity to induce various Th cell responses, this might be a target for therapeutic strategies with the aim of counteracting certain types of Th immune responses by inducing antagonistic $\mathrm{T}$ cells by the same source of skin DCs.

\section{Nature of the T cell infiltrate}

During eczema development, $\mathrm{CD} 4^{+}$Th cells have been regarded as key cells responsible for allergic inflammation of the skin, since high levels of these cells infiltrate into skin lesions. However, recent data from mouse models as well as biopsies taken from atopy patch test induced skin lesions in humans reveal that in addition to $\mathrm{CD} 4^{+} \mathrm{T}$ cells and natural killer $\mathrm{T}$ cells, $\mathrm{CD} 8^{+} \mathrm{T}$ cells might play a pivotal role for the development of eczema, since their number increases immediately after allergen application mostly in the dermis, but also in the epidermis [32]. Moreover, although a subpopulation of CD4 Th cells infiltrating the skin lesions expresses the forkhead-box transcription factor (Foxp)3, which is expressed by regulatory $\mathrm{T}$ cells as well, they are not immunosuppressive, but display functions of effector Th2 cells [33] after stimulation with $S$. aureus enterotoxins in vitro. Furthermore, the concept of Th1/Th2 driven immune responses in AD has been recently revised and extended to Th17 cells, which may play a role in allergic inflammation as well. IL- $4^{+} / \mathrm{IL}-17^{+} \mathrm{T}$ cells have been demonstrated to increase in acute AD, while IL-17 levels are low in chronic AD skin but IL-22 producing Th22 cells might play a role in this phase. In particular $S$. aureus 
alpha toxins induce IL-17 and IL-22 production of T cells in vitro $[34,35]$. The relative absence of IL-17 in chronic AD might promote increased susceptibility to bacterial infections in $\mathrm{AD}$. However, since constitutive capacity of keratinocytes in $\mathrm{AD}$ to upregulate antimicrobial peptide expression in response to IL-17 stimulation in vitro is not modified [36], cofactors in the skin micromilieu such as Th2 cytokines with antagonistic functions to IL-17 might contribute to the attenuated expression of antimicrobial peptides in AD. IL-22 has been demonstrated to contribute to the impaired skin barrier by reducing terminal keratinocyte differentiation and downregulating filaggrin and profilaggrin processing enzymes [37,38]. In this context, the cytokine IL-17E, also known as IL-25 has been demonstrated to be released by dermal DCs in AD. This is of critical immunological importance, since IL-25 enhances Th2 immune responses and reduces filaggrin synthesis thereby impairing the skin barrier [39]. Thus, IL-25 represents an important link between modified skin barrier function and dysfunction at the level of adaptive immune responses in $\mathrm{AD}$.

A role for microRNAs, which are capable of regulating the expression of genes which encode proteins posttranscriptionally in AD skin has not yet been extensively studied. MicroRNAs are capable to mediate translational repression and to destabilize mRNA. A micro RNA which targets the cytotoxic T cell associated antigen (CTLA)-4, was demonstrated to be highly upregulated in lesional $\mathrm{AD}$ skin [40]. In vitro, expression of this microRNA was upregulated during $\mathrm{T}$ cell differentiation and by stimulation of $\mathrm{T}$ cells with S. aureus superantigens as well as nonspecific T cell activation [40]. Since CTLA-4 inhibits activation of T cells, microRNA induced suppression of CTLA-4 function may affect T cells in allergic skin inflammation.

Food allergens are important triggers of AD particularly in children. Both ingestion of food as well as epicutaneous food application are capable of inducing eczematous skin lesions. A recent mouse model of orally immunized mice provided evidence that antigen-specific gut homing $\mathrm{T}$ cells can be reprogrammed to express skin homing molecules in order to be recruited to the skin in response to contact of food allergens with the skin [41]. These data introduce a model in which the plasticity of tissue specific homing receptors on $\mathrm{T}$ cells modifies the migratory properties and direction of $\mathrm{T}$ cells, so that epicutaneous antigen challenge might be capable of promoting the infiltration of $\mathrm{T}$ cells primed in the gut.

Despite reactivity to aeroallergens and food allergens, hyperreactivity to human proteins is regarded as another trigger factor in a subgroup of AD patients. This mechanism is based on cross-reactivity between exogenous and endogenous proteins. T cells cross reactive to Malassezia sympodialis thioredoxin derived from a skin colonizing lipophilic yeast and human thioredoxin has been proposed to be of pathophysiologic relevance in AD [42]. Malassezia sympodialis specific $\mathrm{T}$ cell clones generated from the skin and blood of sensitized AD patients were cross reactive to human thioredoxin, expressed CD4 and the cutaneous lymphocyte antigen and secreted Th1, Th2, Th17 and T22 cytokines [42]. Thus, the allergic hyperreactivity to human proteins might promote chronic skin inflammation in $\mathrm{AD}$ even in the absence of exogenous triggers.

\section{Factors promoting viral spreading in the skin}

A subgroup of $\mathrm{AD}$ patients develops one or more episodes of a severe, disseminated herpes simplex virus skin infection, called eczema herpeticum (EH). Several co-factors have recently been identified, which predispose a subgroup of AD patients to viral skin infections. These include enhanced Th2-polarity, higher number of sensitizations and increased severity of AD [43]. Strong Th2 polarity is of critical immunological importance, since Th2 cytokines dampen several components of the innate and adaptive immune system required for effective viral defense and reduces the expression of proteins in the epidermal 
differentiation complex such as filaggrin and proteins crucial for keratinocyte differentiation including S100/A11 in vitro. Data from mouse models provide evidence for deficient functioning of Foxp3 expressing regulatory $\mathrm{T}$ cells in the skin as another putative cause for uncontrolled viral spreading and disseminated virus infections in AD skin [44]. Whether allergen specific IgE against the virus plays a role as a cofactor, as recently demonstrated for varicella zoster virus specific IgE, which is higher in vaccinated children with AD [45], remains to be determined.

Moreover, transcriptional differences in the interferon (IFN) superfamily were detected in PBMC from patients with AD and history for $\mathrm{EH}$ including lower IFN- $\gamma \mathrm{R}$ expression and IFN- $\gamma$ release. In line with this observation, genetic variants in IFNG and IFNGRI were reported to be associated with $\mathrm{EH}$ and were shown to go along with disseminated viral skin infections in knockout mice [46]. Other genetic modifications shown to be more frequent in the subgroup of AD patients with EH were SNPs in the gene regions encoding thymic stromal lymphopoetin (TSLP), an IL-7 like cytokine which promotes the differentiation of Th2 cells via DCs and the respective IL-7 receptor (IL7R) [47]. On the functional level, some of those genetic modifications might enhance TSLP promoter activity by increasing binding of the activator protein 1 to the regulatory element in the TSLP gene, thereby enhancing TSLP mediated Th2 immune responses certain AD patients.

In addition to a defective adaptive immune response characterized by enhanced $\mathrm{Th} 2$, and defective Th1 responses, comparative proteomic profiling of biopsies from non-lesional and lesional skin of patients with $\mathrm{AD}$ with and without a history for $\mathrm{EH}$ revealed reduced protein levels of filaggrin-2 in tape stripped skin from patients with a history of EH [16]. This is consistent with the concept that defective skin barrier predispose to increased risk for $\mathrm{EH}$ [48]. Patients with a history of EH also have an attenuated induction of the antimicrobial peptides human beta-defensin 2, 3 and cathelicidin under inflammatory conditions [49]. Thus propensity to EH results from a combination of enhanced viral penetration into the skin as the result of skin barrier dysfunction, combined with an inadequate antimicrobial response and impaired adaptive anti-viral immune response.

\section{Concluding remarks}

Recent studies suggest a multitude of cofactors impact at different levels on the pathophysiology and clinical phenotype of $\mathrm{AD}$. However, the key question, which of those factors could be regarded as the hen, and which of them as the egg in this network of events remains still to be answered. In fact, more and more data support a complex pathophysiologic picture of $\mathrm{AD}$ supporting a disease model of skin barrier impairment interacting with components of a hyperreactive allergic response concomitantly with a defective anti-microbial immune system modified by genetic variants [50]. As a consequence, one approach for the future would be to differentiate between factors driving the disease in general from a more individual constellation of trigger factors and mechanisms in particular subgroups of patients. This would hold true for both, preventive as well as mechanism-based therapeutic measures [51].

\section{Acknowledgments}

This project was supported by the Clinical Translational Scientific Award from the National Center for Research Resources, UL1 RR02580, the Atopic Dermatitis Research Network, contract number HHSN272201000020C, and was supported in part by NIAMS grant AR41256 and the Edelstein Family Foundation. 


\section{References}

1. Novak N, Simon D. Atopic dermatitis - from new pathophysiologic insights to individualzed therapy. Allergy. 2011; 66:830-839. [PubMed: 21366605]

*2•. Brown SJ, Asai Y, Cordell HJ, Campbell LE, Zhao Y, Liao H, Northstone K, Henderson J, Alizadehfar R, Ben-Shoshan M, et al. Loss-of-function variants in the filaggrin gene are a significant risk factor for peanut allergy. J Allergy Clin Immunol. 2011; 127:661-667. [PubMed: 21377035] [This is the first genetic study providing evidence for an association of $F L G$ mutations with specific types of food allergies.]

3. Thyssen JP, Carlsen BC, Menne T, Linneberg A, Nielsen NH, Meldgaard M, Szecsi PB, Stender S, Johansen JD. Filaggrin null mutations increase the risk and persistence of hand eczema in subjects with atopic dermatitis: results from a general population study. Br J Dermatol. 2010; 163:115-120. [PubMed: 20426775]

4. O'Regan GM, Irvine AD. The role of filaggrin in the atopic diathesis. Clin Exp Allergy. 2010; 40:965-972. [PubMed: 20642575]

**5•. Barnes KC. An update on the genetics of atopic dermatitis: scratching the surface in 2009. J Allergy Clin Immunol. 2010125:16-29. [This is an excellent review of the complex genetics underlying atopic dermatitis, highlighting the role of gene-environment interactions and the involvement of genes affecting skin barrier as well as the innate and adaptive immune response.]

6. Kezic S, O'Regan GM, Yau N, Sandilands A, Chen H, Campbell LE, Kroboth K, Watson R, Rowland M, Irwin McLean WH, et al. Levels of filaggrin degradation products are influenced by both filaggrin genotype and atopic dermatitis severity. Allergy. 2011; 66:934-940. [PubMed: 21261659]

7. O'Regan GM, Kemperman PM, Sandilands A, Chen H, Campbell LE, Kroboth K, Watson R, Rowland M, Puppels GJ, McLean WH, et al. Raman profiles of the stratum corneum define 3 filaggrin genotype-determined atopic dermatitis endophenotypes. J Allergy Clin Immunol. 2010; 126:574-580. [PubMed: 20621340]

*8•. Miajlovic H, Fallon PG, Irvine AD, Foster TJ. Effect of filaggrin breakdown products on growth of and protein expression by Staphylococcus aureus. J Allergy Clin Immunol. 2010; 126:11841190. [PubMed: 21036388] [The study introduces an interesting connection between genetically predetermined low filaggrin levels in the skin and higher colonization as well as reduced defense of $S$. aureus.]

9. Jakasa I, Koster ES, Calkoen F, McLean WH, Campbell LE, Bos JD, Verberk MM, Kezic S. Skin barrier function in healthy subjects and patients with atopic dermatitis in relation to filaggrin lossof-function mutations. J Invest Dermatol. 2011; 131:540-542. [PubMed: 20962854]

10. Esparza-Gordillo J, Weidinger S, Folster-Holst R, Bauerfeind A, Ruschendorf F, Patone G, Rohde K, Marenholz I, Schulz F, Kerscher T, et al. A common variant on chromosome 11q13 is associated with atopic dermatitis. Nat Genet. 2009; 41:596-601. [PubMed: 19349984]

11. O'Regan GM, Campbell LE, Cordell HJ, Irvine AD, McLean WH, Brown SJ. Chromosome 11q13.5 variant associated with childhood eczema: an effect supplementary to filaggrin mutations. J Allergy Clin Immunol. 2010; 125:170-174. [PubMed: 20109745]

12. Marenholz I, Bauerfeind A, Esparza-Gordillo J, Kerscher T, Granell R, Nickel R, Lau S, Henderson J, Lee YA. The eczema risk variant on chromosome 11q13 (rs7927894) in the population-based ALSPAC cohort: a novel susceptibility factor for asthma and hay fever. Hum Mol Genet. 2011; 20:2443-2449. [PubMed: 21429916]

**13••. Henry J, Hsu CY, Haftek M, Nachat R, de Koning HD, Gardinal-Galera I, Hitomi K, Balica S, Jean-Decoster C, Schmitt AM, et al. Hornerin is a component of the epidermal cornified cell envelopes. FASEB J. 2011; 25:1567-1576. [PubMed: 21282207] [The study emphasizes the role of Hornerin as another component of the mechanical skin barrier deficient in AD.]

**14••. De Benedetto A, Slifka MK, Rafaels NM, Kuo IH, Georas SN, Boguniewicz M, Hata T, Schneider LC, Hanifin JM, Gallo RL, et al. Reductions in claudin-1 may enhance susceptibility to herpes simplex virus 1 infections in atopic dermatitis. J Allergy Clin Immunol. 2011; 128:242246. [PubMed: 21489616] [Evidence that the skin of patients with eczema herpeticum have reduced levels of claudin-1 and defective barrier may enhance viral penetration into their skin.] 
**15••. Suárez-Fariñas M, Tintle SJ, Shemer A, Chiricozzi A, Nograles K, Cardinale I, Duan S, Bowcock AM, Krueger JG, Guttman-Yassky E. Nonlesional atopic dermatitis skin is characterized by broad terminal differentiation defects and variable immune abnormalities. J Allergy Clin Immunol. 2011; 127:954-964. [PubMed: 21388663] [Detailed data about component of the skin barrier and immunologic characteristics in lesional as compared with nonlesional AD skin.]

16. Broccardo CJ, Mahaffey S, Schwarz J, Wruck L, David G, Schlievert PM, Reisdorph NA, Leung DY. Comparative proteomic profiling of patients with atopic dermatitis based on history of eczema herpeticum infection and Staphylococcus aureus colonization. J Allergy Clin Immunol. 2011; 127:186-193. [PubMed: 21211653]

*17•. Dai X, Sayama K, Tohyama M, Shirakata Y, Hanakawa Y, Tokumaru S, Yang L, Hirakawa S, Hashimoto K. Mite allergen is a danger signal for the skin via activation of inflammasome in keratinocytes. J Allergy Clin Immunol. 2011; 127:806-814. [PubMed: 21272927] [One of the first studies providing evidence for a role of the inflammasome in AD.]

18. Niebuhr M, Heratizadeh A, Wichmann K, Satzger I, Werfel T. Intrinsic alterations of proinflammatory mediators in unstimulated and TLR-2 stimulated keratinocytes from atopic dermatitis patients. Exp Dermatol. 2011; 20:468-472. [PubMed: 21447101]

19. Zimmermann M, Koreck A, Meyer N, Basinski T, Meiler F, Simone B, Woehrl S, Moritz K, Eiwegger T, Schmid-Grendelmeier P, et al. TNF-like weak inducer of apoptosis (TWEAK) and TNF-alpha cooperate in the induction of keratinocyte apoptosis. J Allergy Clin Immunol. 2011; 127:200-207. [PubMed: 21211655]

20. Saito M, Nagasawa M, Takada H, Hara T, Tsuchiya S, Agematsu K, Yamada M, Kawamura N, Ariga T, Tsuge I, et al. Defective IL-10 signaling in hyper-IgE syndrome results in impaired generation of tolerogenic dendritic cells and induced regulatory T cells. J Exp Med. 2011; 208:235-249. [PubMed: 21300911]

**21••. Reginald K, Westritschnig K, Linhart B, Focke-Tejkl M, Jahn-Schmid B, Eckl-Dorna J, Heratizadeh A, Stocklinger A, Balic N, Spitzauer S, et al. Staphylococcus aureus fibronectinbinding protein specifically binds $\mathrm{IgE}$ from patients with atopic dermatitis and requires antigen presentation for cellular immune responses. J Allergy Clin Immunol. 2011; 128:82-91. [PubMed: 21513970] [A novel mechanism by which staphylococcus aureus fibronectin-binding protein may elicit cellular immune responses in AD.]

22. Reginald K, Westritschnig K, Werfel T, Heratizadeh A, Novak N, Focke-Tejkl M, Hirschl AM, Leung DY, Elisyutina O, Fedenko E, et al. Immunoglobulin E antibody reactivity to bacterial antigens in atopic dermatitis patients. Clin Exp Allergy. 2011; 41:357-369. [PubMed: 21155910]

$* * 23 \bullet \bullet$. Ziegler SF, Artis D. Sensing the outside world: TSLP regulates barrier immunity. Nat Immunol. 2010; 11:289-293. [PubMed: 20300138] [A sophisticated overview of the recent knowledge about the role of TSLP in regard to the epithelial barrier function and its impact on immunologic pathways.]

**24••. Oyoshi MK, Larson RP, Ziegler SF, Geha RS. Mechanical injury polarizes skin dendritic cells to elicit a $\mathrm{T}(\mathrm{H}) 2$ response by inducing cutaneous thymic stromal lymphopoietin expression. $\mathrm{J}$ Allergy Clin Immunol. 2010; 126:976-984. [PubMed: 21050944] [A novel mechanism is described by which mechanical trauma to the skin could enhance atopic T cell response.]

25. Wu WH, Park CO, Oh SH, Kim HJ, Kwon YS, Bae BG, Noh JY, Lee KH. Thymic stromal lymphopoietin-activated invariant natural killer T cells trigger an innate allergic immune response in atopic dermatitis. J Allergy Clin Immunol. 2010; 126:290-299. [PubMed: 20624642]

26. Gyimesi E, Nagy G, Remenyik E, Sipka S, Zeher M, Biro T, Szegedi A. Altered peripheral invariant natural killer T cells in atopic dermatitis. J Clin Immunol. 2011 [Epub ahead of print].

27. Novak N, Koch S, Allam JP, Bieber T. Dendritic cells: bridging innate and adaptive immunity in atopic dermatitis. J Allergy Clin Immunol. 2010; 125:50-59. [PubMed: 20109736]

28. Voorhees T, Chang J, Yao Y, Kaplan MH, Chang CH, Travers JB. Dendritic cells produce inflammatory cytokines in response to bacterial products from Staphylococcus aureus-infected atopic dermatitis lesions. Cell Immunol. 2011; 267:17-22. [PubMed: 21109237]

29. Peng WM, Yu CF, Kolanus W, Mazzocca A, Bieber T, Kraft S, Novak N. Tetraspanins CD9 and CD81 are molecular partners of trimeric FcvarepsilonRI on human antigen-presenting cells. Allergy. 2011; 66:605-611. [PubMed: 21241315] 
*30•. Gros E, Petzold S, Maintz L, Bieber T, Novak N. Reduced interferon-gamma receptor expression and attenuated interferon- $\gamma$ response by dendritic cells in atopic dermatitis. J Allergy Clin Immunol. 2011 in press. [The study describes attenuated interferon- $\gamma$ response of dendritic cells and their precursors in AD.]

31. Fujita H, Shemer A, Suarez-Farinas M, Johnson-Huang LM, Tintle S, Cardinale I, FuentesDuculan J, Novitskaya I, Carucci JA, Krueger JG, et al. Lesional dendritic cells in patients with chronic atopic dermatitis and psoriasis exhibit parallel ability to activate T-cell subsets. J Allergy Clin Immunol. 2011

*32• Hennino A, Jean-Decoster C, Giordano-Labadie F, Debeer S, Vanbervliet B, Rozieres A, Schmitt AM, Nicolas JF. CD8+ T cells are recruited early to allergen exposure sites in atopy patch test reactions in human atopic dermatitis. J Allergy Clin Immunol. 2011; 127:1064-1067. [PubMed: 21236476] [The authors provide evidence for a role of CD8+ T cells in eczema development.]

33. Lin YT, Wang CT, Chao PS, Lee JH, Wang LC, Yu HH, Yang YH, Chiang BL. Skin-homing CD4+ Foxp3+ T cells exert Th2-like function after staphylococcal superantigen stimulation in atopic dermatitis patients. Clin Exp Allergy. 2011; 41:516-525. [PubMed: 21255144]

34. Niebuhr M, Scharonow H, Gathmann M, Mamerow D. Werfel T: Staphylococcal exotoxins are strong inducers of IL-22: A potential role in atopic dermatitis. J Allergy Clin Immunol. 2010; 126:1176-1183. [PubMed: 20864149]

35. Niebuhr M, Gathmann M, Scharonow H, Mamerow D, Mommert S, Balaji H, Werfel T. Staphylococcal alpha-toxin is a strong inducer of interleukin-17 in humans. Infect Immun. 2011; 79:1615-1622. [PubMed: 21245272]

36. Nograles KE, Suarez-Farinas M, Shemer A, Fuentes-Duculan J, Chiricozzi A, Cardinale I, Zaba LC, Kikuchi T, Ramon M, Bergman R, et al. Atopic dermatitis keratinocytes exhibit normal T(H)17 cytokine responses. J Allergy Clin Immunol. 2010; 125:744-746. [PubMed: 20226306]

*37•. Souwer Y, Szegedi K, Kapsenberg ML, de Jong EC. IL-17 and IL-22 in atopic allergic disease. Curr Opin Immunol. 2010; 22:821-826. [PubMed: 21087848] [The review provides a balanced overview about the role of Th17 and T22 cells in atopic disorders.]

38. Gutowska-Owsiak D, Schaupp AL, Salimi M, Taylor S, Ogg GS. IL-22 down-regulates filaggrin expression and affects expression of profilaggrin processing enzymes. Br J Dermatol. 2011

39. Hvid M, Vestergaard C, Kemp K, Christensen GB, Deleuran B, Deleuran M. IL-25 in atopic dermatitis: a possible link between inflammation and skin barrier dysfunction? J Invest Dermatol. 2011; 131:150-157. [PubMed: 20861853]

*40•. Sonkoly E, Janson P, Majuri ML, Savinko T, Fyhrquist N, Eidsmo L, Xu N, Meisgen F, Wei T, Bradley M, et al. MiR-155 is overexpressed in patients with atopic dermatitis and modulates Tcell proliferative responses by targeting cytotoxic T lymphocyte-associated antigen 4. J Allergy Clin Immunol. 2010; 126:581-589. [PubMed: 20673989] [First study about microRNA regulated mechanisms in AD.]

**41••. Oyoshi MK, Elkhal A, Scott JE, Wurbel MA, Hornick JL, Campbell JJ, Geha RS. Epicutaneous challenge of orally immunized mice redirects antigen-specific gut-homing $\mathrm{T}$ cells to the skin. J Clin Invest. 2011; 121:2210-2220. [PubMed: 21537081] [Interesting conceptual insights into the plasticity of gut-homing, antigen-specific $\mathrm{T}$ cells and their redirection to the skin.]

42. Balaji H, Heratizadeh A, Wichmann K, Niebuhr M, Crameri R, Scheynius A, Werfel T. Malassezia sympodialis thioredoxin-specific $\mathrm{T}$ cells are highly cross-reactive to human thioredoxin in atopic dermatitis. J Allergy Clin Immunol. 2011; 128:92-99. [PubMed: 21489611]

43. Hinz T, Zaccaro D, Byron M, Brendes K, Krieg T, Novak N, Bieber T. Atopic dermo-respiratory syndrome is a correlate of eczema herpeticum. Allergy. 2011; 66:925-933. [PubMed: 21255038]

44. Freyschmidt EJ, Mathias CB, Diaz N, MacArthur DH, Laouar A, Manjunath N, Hofer MD, Wurbel MA, Campbell JJ, Chatila TA, et al. Skin inflammation arising from cutaneous regulatory $\mathrm{T}$ cell deficiency leads to impaired viral immune responses. J Immunol. 2010; 185:1295-1302. [PubMed: 20548030]

45. Schneider L, Weinberg A, Boguniewicz M, Taylor P, Oettgen H, Heughan L, Zaccaro D, Armstrong B, Holliday A, Leung DY. Immune response to varicella vaccine in children with 
atopic dermatitis compared with nonatopic controls. J Allergy Clin Immunol. 2010; 126:13061307. [PubMed: 20889193]

*46•. Leung DY, Gao PS, Grigoryev DN, Rafaels NM, Streib JE, Howell MD, Taylor PA, Boguniewicz M, Canniff J, Armstrong B, et al. Human atopic dermatitis complicated by eczema herpeticum is associated with abnormalities in IFN-gamma response. J Allergy Clin Immunol. 2011; 127:965-973. [PubMed: 21458658] [The study provides insights into genetic modifications of $I F N G$ with putative functional consequences increasing the susceptibility to disseminated HSV infections in a subgroup of patients.]

**47••. Gao PS, Rafaels NM, Mu D, Hand T, Murray T, Boguniewicz M, Hata T, Schneider L, Hanifin JM, Gallo RL, et al. Genetic variants in thymic stromal lymphopoietin are associated with atopic dermatitis and eczema herpeticum. J Allergy Clin Immunol. 2010; 125:1403-1407. [PubMed: 20466416] [Further support for the concept that increased Th2 polarity predisposes to eczema herpeticum.]

48. Gao PS, Rafaels NM, Hand T, Murray T, Boguniewicz M, Hata T, Schneider L, Hanifin JM, Gallo RL, Gao L, Beaty TH, Beck LA, Barnes KC, Leung DY. Filaggrin mutations that confer risk of atopic dermatitis confer greater risk for eczema herpeticum. J Allergy Clin Immunol. 2009; 124:507-513. [PubMed: 19733298]

49. Hata TR, Kotol P, Boguniewicz M, Taylor P, Paik A, Jackson M, Nguyen M, Kabigting F, Miller $\mathrm{J}$, Gerber M, et al. History of eczema herpeticum is associated with the inability to induce human beta-defensin (HBD)-2, HBD-3 and cathelicidin in the skin of patients with atopic dermatitis. Br J Dermatol. 2010; 163:659-661. [PubMed: 20545685]

50. Boguniewicz M, Leung DY. Recent insights into atopic dermatitis and implications for management of infectious complications. J Allergy Clin Immunol. 2010; 125:4-13. [PubMed: 20109729]

51. Guttman-Yassky E, Nograles KE, Krueger JG. Contrasting pathogenesis of atopic dermatitis and psoriasis: Part II: Immune cell subsets and therapeutic concepts. J Allergy Clin Immunol. 2011; 127:1420-1432. [PubMed: 21419481] 


\section{Highlights}

- Atopic Dermatitis is the most common inflammatory skin disease in the general population

- Atopic Dermatitis is a genetic disease triggered by infection, allergens and stress

- Atopic dermatitis results from barrier defects combined with abnormal innate and adaptive immune responses 